\title{
Fatal bacterial septicemia in a bottlenose dolphin Tursiops truncatus caused by Streptococcus iniae
}

\author{
Zhiqi Song ${ }^{1}$, Ruichao Yue ${ }^{1}$, Yanming Sun ${ }^{2}$, Chunfa Liu ${ }^{1}$, Sher Hayat Khan ${ }^{1}$, \\ Chaosi Li ${ }^{1}$, Ying Zhao ${ }^{1}$, Xiangmei Zhou ${ }^{1}$, Lifeng Yang ${ }^{1}$, Deming Zhao ${ }^{1, *}$ \\ ${ }^{1}$ The State Key Laboratories for Agrobiotechnology, Key Lab of Animal Epidemiology and Zoonosis, \\ Ministry of Agriculture; National Animal Transmissible Spongiform Encephalopathy Laboratory; Department of Veterinary \\ Pathology, College of Veterinary Medicine, China Agricultural University, Beijing 100193, PR China \\ ${ }^{2}$ Beijing Aquarium, Beijing 100081, PR China
}

\begin{abstract}
A captive 8 yr old male bottlenose dolphin Tursiops truncatus succumbed to septicemia with multisystemic inflammation including suppurative enteritis, encephalitis, and pneumonia with chronic pancreatitis. A pure culture of beta-hemolytic, catalase- and oxidase-negative, Gram-positive cocci was isolated from the hilar lymph nodes and pancreas. The isolate was identified by $16 \mathrm{~S}$ rDNA sequencing as Streptococcus iniae. Histological examination of the digestive system revealed a mixed infection of both bacteria and fungus. Recognized as a pathogen in fish, dolphins, and humans, this is the first report of $S$. iniae in a dolphin in mainland China. As the number of managed animals in oceanariums is increasing, so is the frequency of contact with fish used as food for marine mammals and humans, highlighting the importance of education and appropriate personal protective protocols to minimize the risk of transmission. An understanding of marine mammal infectious disease organisms is essential to ensuring the health of marine mammals and humans coming into contact with such animals and their food. This study illustrates a systematic clinical, microbiological, and pathological investigation into a septicemic bottlenose dolphin infected with $S$. iniae. Our findings provide useful information for those involved in the diagnosis and control of infectious diseases in marine mammals and offer insight into an important zoonotic pathogen.
\end{abstract}

KEY WORDS: Streptococcus iniae $\cdot$ Bottlenose dolphin $\cdot$ Zoonosis

\section{INTRODUCTION}

Inhabiting the same inshore ecosystems used by humans, marine mammals, as long-lived, top-tier consumers, are sentinel species for both human and ocean health (Bossart et al. 2011). Knowledge of the diversity and distribution of marine mammal pathogens is expanding rapidly (Maness et al. 2011, Rivera et al. 2012). Recent studies have underscored the importance of domesticated and feral animal populations in both the emergence of novel, and the re-emergence of existing, human pathogens (Woolhouse \& Gowtage-Sequeria 2005). Streptococcus iniae was first isolated in 1976 from skin lesions of Amazon freshwater dolphins Inia geoffrensis in the USA (Pier \& Madin 1976), and is considered a major aquatic animal pathogen in many regions of the world. Since then, many outbreaks of $S$. iniae infection with high mortality rates in aquaculture farms have been reported, with numerous fish species being found to be susceptible to infection (Adams \& Thompson 2006), including a variety of ornamental fish (Hartman et al. 2006). These bacteria are also zoonotic with infections in humans associated with the handling and preparation of infected fish. Based on the data from the Centers for Disease Control and 
Prevention Microbiology Laboratory, the bacterium was first recognized to cause human infection in 1991 in North America (Centers for Disease Control 1996).

$S$. iniae tends to cause different disease states depending on the type of host it infects. In dolphins, this bacterium was only associated with dermatitis and cellulitis and caused multifocal subcutaneous abscesses in 3 I. geoffrensis (Pier \& Madin 1976, Pier et al. 1978, Bonar \& Wagner 2003). In fish, infection with $S$. iniae generally results in meningitis and panophthalmitis, and consequently, high levels of morbidity and mortality (Bromage \& Owens 2002). Humans tend to develop a septic cellulitis, with occasional endocarditis, meningitis, arthritis, sepsis, pneumonia, osteomyelitis, and toxic shock (Weinstein et al. 1997, Facklam et al. 2005). Sun et al. (2007) described a case report of an invasive $S$. iniae infection in a $51 \mathrm{yr}$ old woman with diabetes mellitus and hepatitis C-related liver cirrhosis in Taiwan in 2007. In dolphins, few cases were associated with $S$. iniae infection (Bonar \& Wagner 2003). However, $S$. iniae has not received much attention or been reported previously in mainland China. While there are vaccines available for fish and antibiotics that can successfully treat this bacterium, the risk of transmission is of significant concern for individuals handling fish or marine mammal carcasses, since an untreated infection could lead to permanent tissue damage or death. Moreover, there are no effective bacterins for use in dolphins. Here, we report a systematic clinical, microbiological, and pathological investigation of $S$. iniae infection in a deceased 8 yr old male bottlenose dolphin Tursiops truncatus. This Tursiops case shows the first report of $S$. iniae being related to a disseminated suppurative inflammatory process. Our findings highlight the need for clinicians to be vigilant for cases of $S$. iniae infection and for microbiology laboratory staff to pay particular attention to specimens from patients with a history of fish handling.

\section{MATERIALS AND METHODS}

\section{Clinical history and therapeutic measures}

A $100 \mathrm{~kg}, 225 \mathrm{~cm}, 8$ yr old male Tursiops truncatus originally from Japan died on 2 April 2015 following an extended illness and was necropsied within $24 \mathrm{~h}$. The animal had been housed at Beijing aquarium since 15 September 2010, when it was 3 yr old. The clinical history indicated occasional traumatic skin lesions as a result of fighting with another male dolphin housed in the same pool from April to October
2013. The dolphin recovered from a caudal vertebral muscle abscess with secondary vestibular sac prolapse and spondylarthritis after the administration of long-term antibiotic treatment from December 2013 to May 2014, using mainly clindamycine and cefdinir. No bacteriology was undertaken on initial clinical presentation. Following this treatment, the dolphin had been in good health. However, approximately 11 mo later, slow, weak swimming was noted on 5 March 2015. Increased white blood cell count $\left(15 \times 10^{3} \mathrm{~mm}^{-3}\right)$ and a marked left shift of neutrophils in the blood indicated infection. Alkaline phosphatase (60 IU ${ }^{-1}$ ) was markedly decreased, and alanine aminotransferase (85 IU ${ }^{-1}$ ) was moderately increased. Creatine kinase values, creatinine, bilirubin, aspartate aminotransferase, other enzymes, and electrolytes were within reference ranges (Zappulli et al. 2005).The clinical manifestations that followed and the therapeutic measures taken are presented in Table 1.

\section{Necropsy and histopathology}

A full necropsy was performed with tissue samples taken from all organs and fixed in $10 \%$ formalin for histologic evaluation using hematoxylin and eosin (H\&E) staining. Aerobic bacterial cultures were obtained from the lung, hilar lymph nodes, liver, pancreas, and digestive tract. A gram-positive coccus was isolated from the hilar lymph nodes and pancreas on blood agar and trypticase soy agar incubated at $25^{\circ} \mathrm{C}$ for $24 \mathrm{~h}$. The genus of the bacterium was identified using a conventional rapid identification system (API 20 Strep), and the species was verified using 16S rRNA gene partial sequencing (Zhang et al. 2000, El Aamri et al. 2010) with BLAST analysis.

\section{RESULTS}

\section{Gross and histopathological assessment}

Gross necropsy findings included mild to moderate enlargement and hyperemia of the hilar lymph nodes. A pale yellow thick exudate composed principally of neutrophils admixed with cellular debris, edema fluid, and fibrin was present in the subarachnoid space on the dorsal surface of the brain and also in sulci. The gyri were flattened, indicating brain swelling and secondary compression. The liver and pancreas had moderate to severe swelling. On the surface of the lungs were multifocal yellow and white 
Table 1. Clinical manifestations observed and the therapeutic measures instituted during the illness of a captive bottlenose dolphin Tursiops truncatus in 2015; p.o.: by mouth; b.i.d.: twice $\mathrm{d}^{-1}$; s.i.d.: once $\mathrm{d}^{-1}$; t.i.d.: 3 times $\mathrm{d}^{-1}$; i.m.: intramuscular injection; i.v.: intravenous injection

\begin{tabular}{|c|c|c|}
\hline Duration of treatment & Clinical manifestations & Therapeutic measures \\
\hline 5-12 March & $\begin{array}{l}\text { Anepithymia, slow weak swimming, } \\
\text { leukocytosis neutrophilia with left shift }\end{array}$ & Clindamycin: $10 \mathrm{mg} \mathrm{kg}^{-1}$, p.o., b.i.d. \\
\hline 13-19 March & $\begin{array}{l}\text { Depression, anepithymia, occasional sinking, } \\
\text { slight high temperature, leukocytosis } \\
\text { neutrophilia with left shift }\end{array}$ & $\begin{array}{l}\text { Levofloxacin hydrochloride: } 5 \text { mg kg}{ }^{-1} \text {, p.o., b.i.d. } \\
\text { Metronidazole: } 7 \mathrm{mg} \mathrm{kg}^{-1} \text {, p.o., b.i.d. }\end{array}$ \\
\hline 20-23 March & $\begin{array}{l}\text { Depression, occasional anepithymia, } \\
\text { high temperature, leukocytosis neutrophilia } \\
\text { with left shift }\end{array}$ & $\begin{array}{l}\text { Ceftriaxone sodium: } 20 \mathrm{mg} \mathrm{kg}^{-1}, 2 \mathrm{~g} \text { each time, } \\
\text { i.m., s.i.d. } \\
\text { Sucralfate: } 1 \mathrm{~g} \text { each time, p.o., t.i.d. }\end{array}$ \\
\hline 24-27 March & $\begin{array}{l}\text { Vomiting, high temperature, slow and weak } \\
\text { swimming, sometimes just floating }\end{array}$ & $\begin{array}{l}\text { Cefdinir capsules: } 6 \mathrm{mg} \mathrm{kg}^{-1} \text {, p.o., b.i.d. } \\
\text { Ivermectin tablets: } 0.2 \mathrm{mg} \mathrm{kg}^{-1} \text {, p.o., s.i.d. }\end{array}$ \\
\hline 28 March - 1 April & $\begin{array}{l}\text { Vomiting, slow and weak swimming, } \\
\text { sometimes erratic behavior, increased } \\
\text { floating time, left lateral tilt observed }\end{array}$ & $\begin{array}{l}\text { Ceftriaxone sodium: } 20 \mathrm{mg} \mathrm{kg}^{-1}, 2 \mathrm{~g} \text { each time, } \\
\text { i.m., s.i.d. } \\
\text { Imipenem and cilastatin sodium: } 10 \mathrm{mg} \mathrm{kg}^{-1} \text {, i.v., } \\
\text { b.i.d. } \\
\text { Praziquantel: } 3 \mathrm{mg} \mathrm{kg}^{-1} \text {, p.o., s.i.d. }\end{array}$ \\
\hline 2 April & $\begin{array}{l}\text { Respiratory frequency increased, abnormal } \\
\text { breathing patterns, loss of orientation, } \\
\text { displayed swimming disorders compatible } \\
\text { with neurological syndromes, died at 02:46 h }\end{array}$ & $\begin{array}{l}\text { All rescue measures proved ineffectual and } \\
\text { death occurred }\end{array}$ \\
\hline
\end{tabular}

nodules ranging in the size from 1 to $1.5 \mathrm{~cm}$ in diameter. The lung parenchyma was variably inflated, consolidated, and mottled dark red to mahogany. The lung cut surface and major bronchus contained an exudate. The bronchial lymph node was moderately enlarged and diffusely hyperemic. Numerous petechiae were present on the right ventricular myocardium. In addition, there were multiple congestion gastric erosions and diffuse hyperemia of the intestinal mucosa.

Histopathology revealed multisystemic suppurative inflammation characterized by a predominant neutrophilic infiltration with acute bacterial sepsis, fungal infection, and chronic inflammation. The predominant lesions in the brain included suppurative encephalitis (Fig. 1) and hemorrhagic meningitis, along with abscess formation characterized by the infiltration of inflammatory cells, multifocal infiltration of macrophages and necrotic cellular debris, and mononuclear cell perivascular cuffing. Neuronal degeneration, microgliosis, satellitosis, neuronophagia, and occasional presence of multinucleate syncytia were observed, with these changes mostly affecting the cortical and subcortical gray matter. The lungs showed acute suppurative bronchopneumonia (Fig. 2A,B) with hyperemia, abundant neutrophils, macrophages, and cellular debris within the lumen of bronchi, bronchioles, and alveoli. Bile duct prolifera- tion was present in the liver accompanied by focal inflammation (Fig. 2C,D) while the pancreas exhibited chronic inflammation histologically (Fig. 3). The intestinal tract showed suppurative gastritis (mainly the second gastric chamber) and enteritis (Fig. 4A). Numerous multifocal to coalescing basophilic fungal organisms were pigmented on HE-stained sections in the digestive tract. Tight clusters of fungal hyphae were diffusely arranged, with a radial or coralloid appearance (Fig. 4C). Large amorphous aggregates were characterized by necrotic cell debris containing hyphae with regularly septate parallel basophilic walls, and dichotomous acute angle branching (Fig. 4D), surrounded by Langhans multinucleated giant cells and variable numbers of neutrophils, lymphocytes, epithelioid macrophages, and fibroblasts (Fig. 4B-D). The cause of death for this dolphin was multifactorial associated with bacterial and fungal pathogens.

\section{Phenotypic characterization and PCR results}

A catalase and oxidase negative $\beta$-hemolytic Grampositive coccus was isolated from the hilar lymph nodes and pancreas. The API 20 Strep test (Zhou et al. 2008, El Aamri et al. 2010) result was unable to identify the Streptococcus species (Table 2). Molecu- 


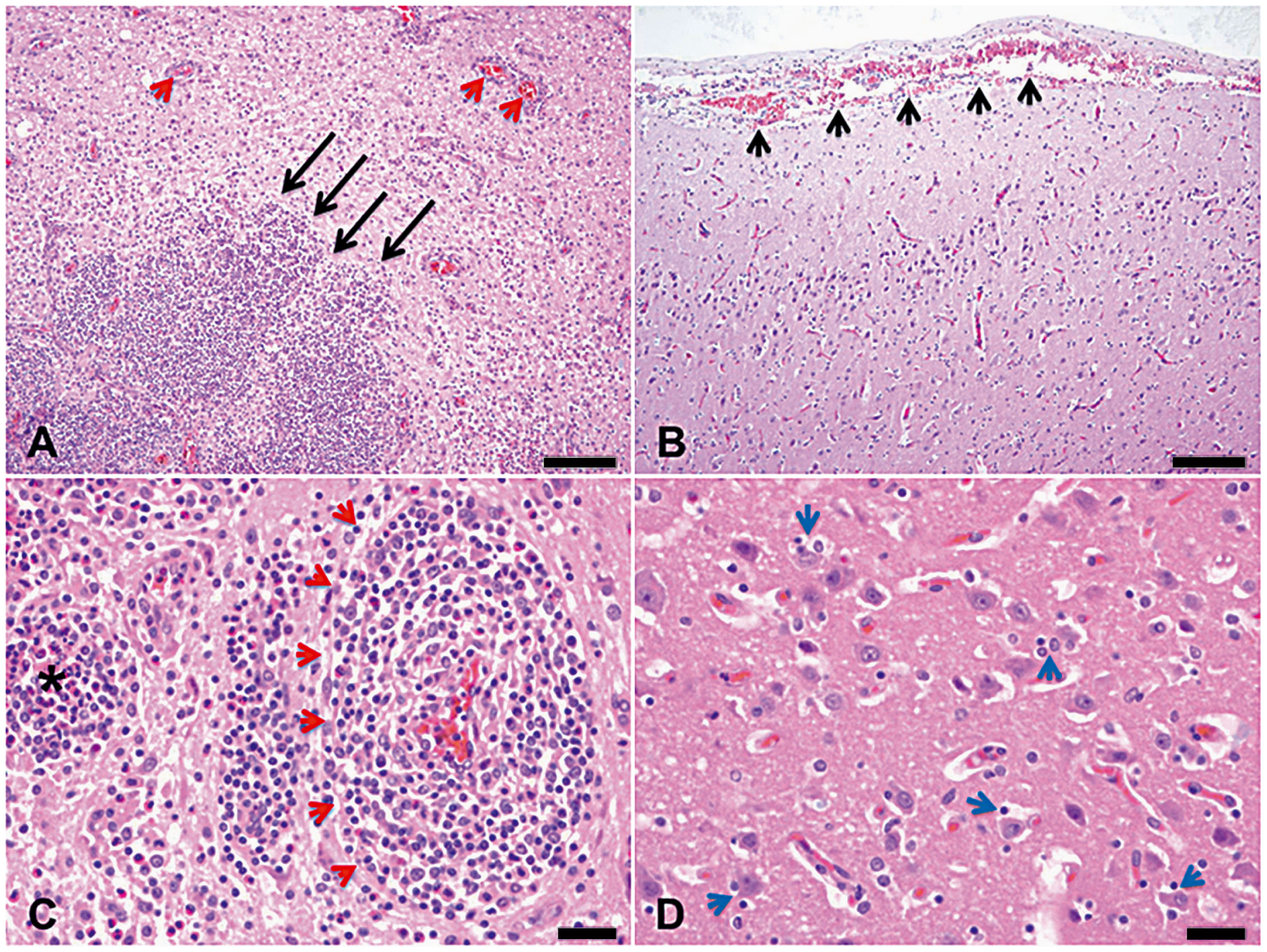

Fig. 1. Histopathological analysis of the brain of a diseased Tursiops truncatus (H\&E stain). (A) Suppurative encephalitis. In the cortex and sub-cortex areas, multifoci are evident, with abscesses that vary in size (black arrows). Perivascular inflammatory cell infiltration is also indicated (red arrowheads). (B) Hemorrhagic meningitis. Hemorrhaging and edema are evident under the meninges (black arrowheads), along with diffuse inflammatory cells. (C) Perivascular cuffing. Monocytes (red arrowheads) in the perivascular space have been recruited from the vasculature and form several layers of cuffing. Higher magnification of a small abscess (black asterisk) that contains neutrophils, other mononuclear inflammatory cells, and cellular debris. (D) Satellitosis and neuronophagia. This necrotic neuron cell body is surrounded by macrophages or microglia that will phagocytose the cell debris (blue arrowheads). Scale bars $=(A, B) 100 \mu \mathrm{m},(C, D) 20 \mu \mathrm{m}$

lar identification based on sequencing of the 16S rRNA gene was performed to confirm the biochemical identification. A polymerase chain reaction-amplified product of the 16S rRNA gene was sequenced, and the sequence obtained was subjected to BLAST analysis against the National Center for Biotechnology Information (NCBI) database. The 1011 bp fragment showed $100 \%$ similarity with sequence AF335572 (type strain NR 025148; El Aamri et al. 2010), identifying the isolated strain as $S$. iniae.

\section{DISCUSSION}

Streptococcosis is classically associated with acute and chronic mortality in many aquaculture species, with Streptococcus iniae causing meningoencephalitis, systemic septicemia, and subsequent mortality in fish. At least 27 species of fish have been documented to be infected by $S$. iniae worldwide (Agnew \& Barnes 2007), with the exception of mainland China. The risk of zoonotic transmission of $S$. iniae from 

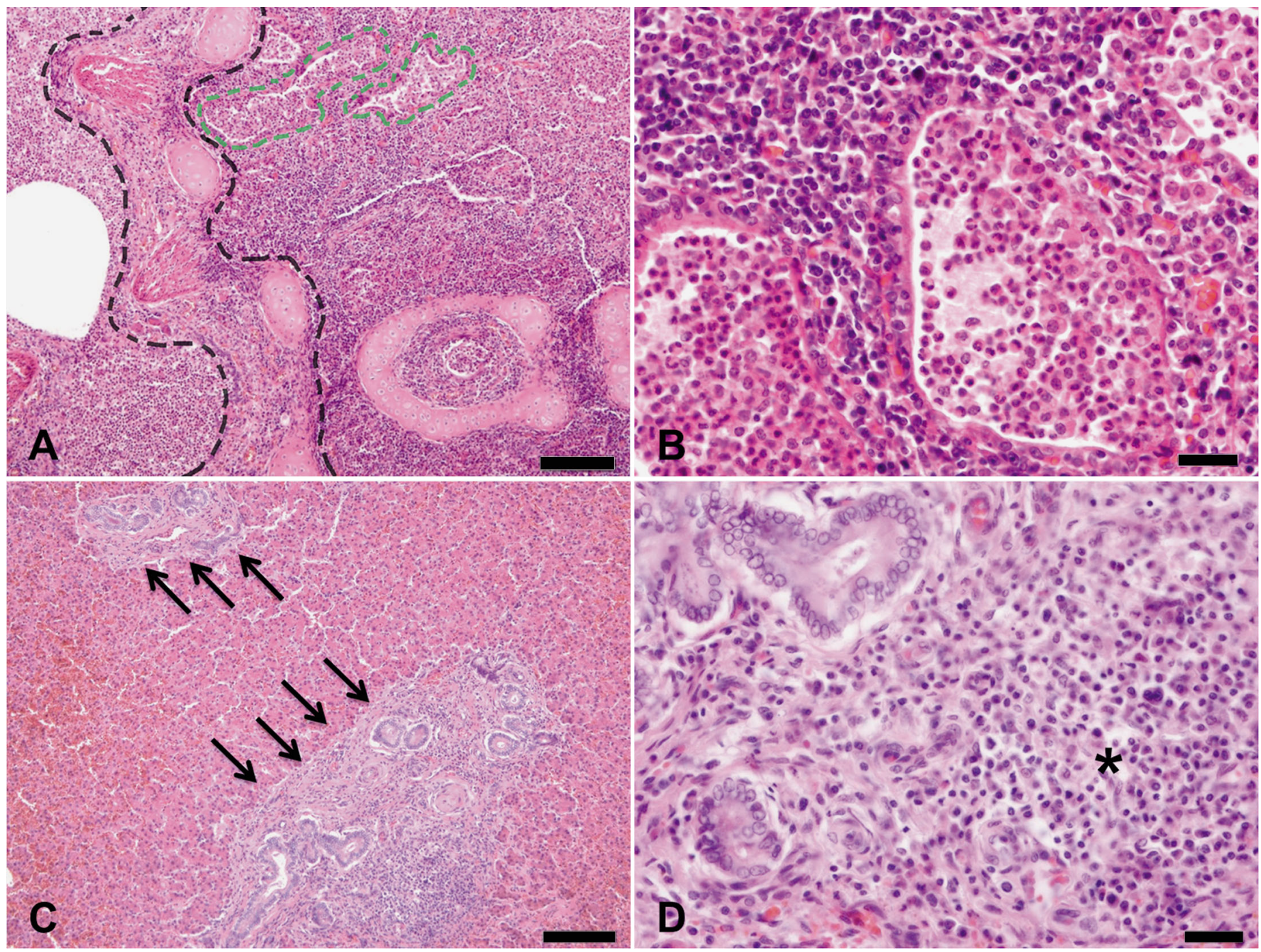

Fig. 2. Histopathological analysis of the lung and liver of a diseased Tursiops truncatus (H\&E stain). (A) Chronic suppurative pneumonia. The trachea (black dotted line) and alveoli (green dotted line) contain numerous neutrophils and macrophages. Alveoli are edematous and contain similar inflammatory cells. (B) Higher magnification of pulmonary alveoli. Alveolar septa are widened by inflammation. Some of the neutrophils along with edema fluid and fibrinous exudate appear to be migrating from the capillaries of the lamina propria of the bronchiole into the alveoli. (C) Chronic active fibrosing cholangiohepatitis with biliary hyperplasia. Proliferation of biliary ducts (black arrows) within the portal areas and periportal regions. (D) Higher magnification of biliary hyperplasia. The hypertrophied and hyperplastic bile ducts are surrounded by apparently randomly arranged bands of fibrous connective tissue and focal inflammatory cells (black asterisk). Scale bars $=(A, C) 100 \mu m,(B, D) 20 \mu \mathrm{m}$

cetaceans to humans is unknown; however, it is known to be a zoonotic pathogen leading to disease in those directly handling infected fish. For example, fresh whole fish are often purchased from retail wet markets followed by scaling, cutting, and removal of fins and internal organs with bare hands. Many predisposing or environmental factors have been identified that enhance the virulence associated with this infection (Lau et al. 2007).

In the case of the deceased dolphin described in this report, the cause of death was complex with a number of potential contributing factors. The gross necropsy, histopathology results, and the microbiology evaluation indicated the cause of death to be associated with a systemic $S$. iniae infection. The involvement of the fungi in the intestinal tract suggested further immune compromise with this individual prior to death.

The clinical and medication history of this dolphin cannot be ruled out as predisposing cofactors for septicemia and antibiotic resistance. The long-term use of antibiotics may have suppressed the immunity 


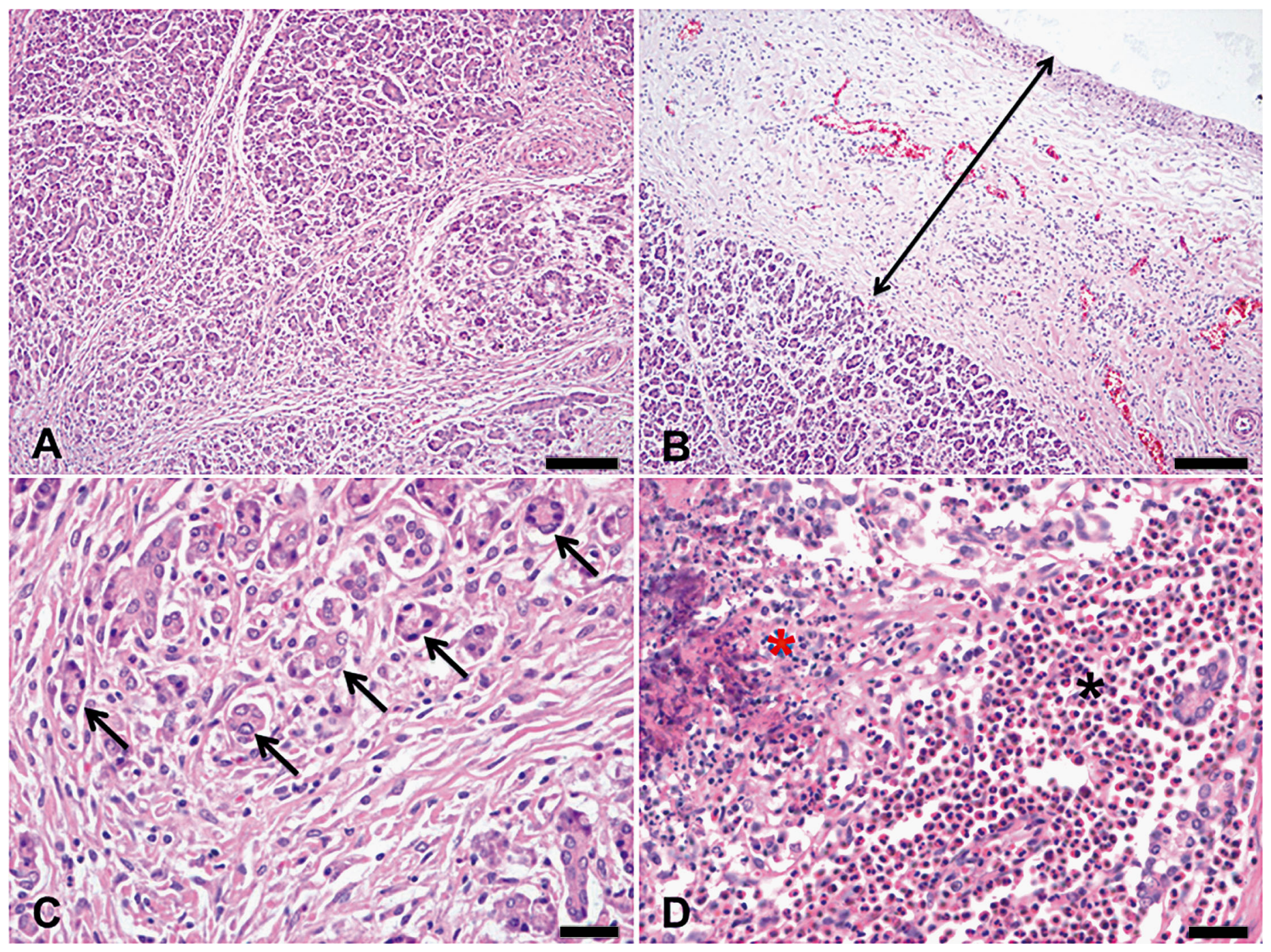

Fig. 3. Histopathological analysis of the pancreas of a diseased Tursiops truncatus (H\&E stain). (A,B) Chronic active pancreatitis with varying degrees of interlobular and dissecting intralobar fibrosis with parenchymal atrophy. Note the severe widened interstitial fibrosis and edema of the pancreas (double-headed arrow). Scale bars $=100 \mu$ m. (C,D) Higher magnification of chronic pancreatitis. The remaining exocrine pancreatic cells appear separated into small lobules (black arrows) by abundant fibrous connective tissue. Note the infiltration of plentiful neutrophils (black asterisk) around the residual pancreatic acini and the necrotic cell debris (red asterisk). Scale bars $=20 \mu \mathrm{m}$

of this animal, as well as increasing the risk of bacterial drug resistance during therapy and altered microflora, with increased susceptibility to infection. Streptococci are normally highly sensitive to penicillin, which was not selected for therapy in this case. The infection spread hematogenously and crossed the blood-brain barrier. The suppurative encephalitis observed suggested infection with a more virulent strain that was able to evade intracellular killing, and this warrants further investigation. Pseudohyphae and multinuclear giant cells were observed in the digestive system, indicative of a long-term pseudo- hyphal and yeast infection; however, antifungal drugs were not used during the course of treatment and the species of fungus was not determined. Yeast infection with pseudohyphae cannot be conclusively excluded as a contributor in the disease course and in the ultimate demise of the animal.

Mycotic diseases in delphinoids have been seen under a number of circumstances, and pathogenic fungal species have been isolated from their exhalation (Buck et al. 2006). Some of these species are environmental contaminants, whereas others such as Candida albicans and other Candida spp. are part of the normal micro- 

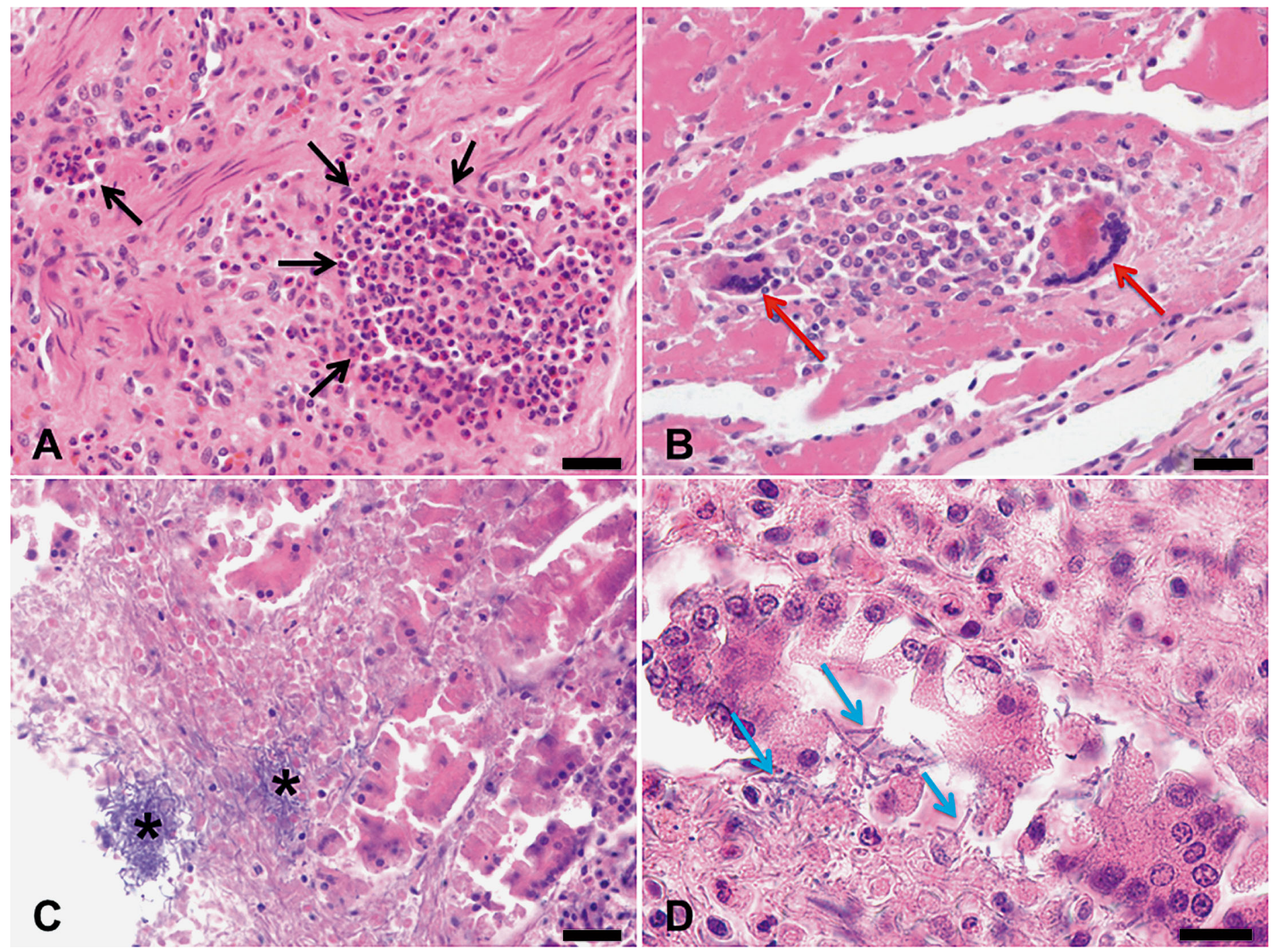

Fig. 4. Histopathological analysis of the digestive tract of a diseased Tursiops truncatus (H\&E stain). (A) Suppurative gastritis (the second gastric chamber). Multifocal inflammatory cells containing neutrophils, other mononuclear inflammatory cells, and cellular debris in the muscular layer of the stomach (black arrows). (B) Granulomatous enteritis. Mononuclear inflammatory cells (macrophages, lymphocytes) and multinucleated giant cells (red arrows) are present in the lamina propria and sub mucosa. (C) Pseudohyphae. The epithelia of the intestine appear markedly compressed by pseudohyphae and necrotic cell debris, resulting in their exfoliation and loss (black asterisk). (D) Higher magnification of the pseudohyphae (blue arrows). Scale bars $=(A-C) 20 \mu \mathrm{m},(\mathrm{D}) 10 \mu \mathrm{m}$

flora of mucous membranes (Buck et al. 2006, Takahashi et al. 2010). Additionally, a correlation between the occurrence of lobomycosis and the immune status of free-ranging dolphins was reported in bottlenose dolphins in Florida, USA (Murdoch et al. 2008, Durden et al. 2009, Reif et al. 2009). Human pathogenic yeast species were isolated from more than $70 \%$ of captive dolphins and environmental water samples, which were higher rates than in wild dolphins (Buck 1980). Administration of antibiotics and steroids among captive dolphins might be a contributing factor with environmental and social stress for this observation (Bagg et al. 2003,
Melo et al. 2004). However, further studies are needed to investigate correlations between stress and immunosuppression, host defense mechanisms and infection rates, and drug metabolism in these animals.

This dolphin was likely in a long-term weakened state (chronically ill) compounded by a chronic mycotic infection, and succumbed to an acute streptococcosis septicemia. Metabolic disorders associated with pancreatic destruction coupled with suppressed immunity were therefore considered confounding factors in the causes of death. High-risk factors for $S$. iniae infection in humans also include compro- 
Table 2. Phenotypic characterization of Streptococcus iniae isolated from a diseased captive bottlenose dolphin Tursiops truncatus

\begin{tabular}{|lc|lc|}
\hline API 20 STREP test & Result & API 20 STREP test & Result \\
\hline Hemolysis & $\beta$ & Mannitol & + \\
Oxidase & - & Sorbitol & - \\
Catalase & - & Lactose & - \\
Pyrrolidonyl arylamidase & + & Trehalose & + \\
Voges Proskauer & - & Inulin & - \\
Hippurate hydrolysis & - & Raffinose & - \\
Esculine degradation & + & Amidon & + \\
$\alpha$-galactosidase & - & Glycogen & + \\
$\beta$-glucuronidase & + & Arginine & + \\
$\beta$-galactosidase & - & Lysine & - \\
Alkaline phosphatase & + & Ornithine & - \\
Leucine aminopeptidase & + & Indol & - \\
Arginine dihydrolase & + & Kligler $\mathrm{H}_{2}$ S production & - \\
Ribose & + & Urease & - \\
Arabinose & - & Nitrate reduction & - \\
\hline
\end{tabular}

mised immunity, underlying medical conditions, old age, and Asian ethnicity (Koh et al. 2004, Lau et al. 2007, Sun et al. 2007). With the number of animals managed in oceanariums, rehabilitation facilities, and research facilities, the contact between marine mammals and humans is increasing. Furthermore, as coastal communities expand, opportunities for encounters with marine wildlife increase the potential for zoonotic disease transmission. Marine mammal researchers, rehabilitators, trainers, veterinarians, volunteers, and subsistence hunters have an increased risk of injury and exposure to zoonotic diseases through extended occupational exposure. Information on marine mammal pathology is scarce in the published literature; the information presented here will therefore be useful for public health professionals, pathologists, veterinarians, and wildlife biologists involved in handling cetaceans.

As the clinical manifestations of a chronic illness or an acutely ill animal may not be outwardly apparent, appropriate personal protective precautions should be taken until the absence of zoonotic agents is confirmed in any suspected case. We hope that the information on animal disease encountered in managed and wild cetaceans will be used by public health professionals, veterinarians, wildlife biologists, and pathologists to better understand, diagnose, and prevent marine mammal zoonoses and to improve the welfare of animals in China and the rest of the world.

Acknowledgements. This work was supported by the Foundation of Chinese Ministry of Science and Technology (Project Nos. 2015BAI09B01 and 2015BAI07B02)

\section{LITERATURE CITED}

Adams A, Thompson KD (2006) Biotechnology offers revolution to fish health management. Trends Biotechnol 24: 201-205

Agnew W, Barnes A (2007) Streptococcus iniae: an aquatic pathogen of global veterinary significance and a challenging candidate for reliable vaccination. Vet Microbiol 122:1-15

*Bagg J, Sweeney MP, Lewis MA, Jackson MS and others (2003) High prevalence of non-albicans yeasts and detection of anti-fungal resistance in the oral flora of patients with advanced cancer. Palliat Med 17:477-481

Bonar CJ, Wagner RA (2003) A third report of 'golf ball disease' in an Amazon River dolphin (Inia geoffrensis) associated with Streptococcus iniae. J Zoo Wildl Med 34: 296-301

* Bossart GD, Romano TA, Peden-Adams MM, Schaefer A and others (2011) Clinicoimmunopathologic findings in Atlantic bottlenose dolphins Tursiops truncatus with positive cetacean morbillivirus antibody titers. Dis Aquat Org 97:103-112

* Bromage ES, Owens L (2002) Infection of barramundi Lates calcarifer with Streptococcus iniae: effects of different routes of exposure. Dis Aquat Org 52:199-205

Buck JD (1980) Occurrence of human-associated yeasts in the feces and pool waters of captive bottlenosed dolphins (Tursiops truncatus). J Wildl Dis 16:141-149

Buck JD, Wells RS, Rhinehart HL, Hansen LJ (2006) Aerobic microorganisms associated with free-ranging bottlenose dolphins in coastal Gulf of Mexico and Atlantic Ocean waters. J Wildl Dis 42:536-544

Centers for Disease Control and Prevention (CDC) (1996) Invasive infection with Streptococcus iniae-Ontario, 1995-1996. MMWR Morb Mortal Wkly Rep 45:650-653

Durden WN, St LJ, Stolen M, Mazza T, Londono C (2009) Lacaziosis in bottlenose dolphins (Tursiops truncatus) in the Indian River Lagoon, Florida, USA. J Wildl Dis 45: 849-856

El Aamri F, Padilla D, Acosta F, Caballero MJ and others (2010) First report of Streptococcus iniae in red porgy (Pagrus pagrus, L.). J Fish Dis 33:901-905

Facklam R, Elliott J, Shewmaker L, Reingold A (2005) Identification and characterization of sporadic isolates of Streptococcus iniae isolated from humans. J Clin Microbiol 43:933-937

Hartman KH, Yanong RP, Harms CA, Lewbart GA (2006) The future of training for aquatic animal health veterinarians. J Vet Med Educ 33:389-393

Koh TH, Kurup A, Chen J (2004) Streptococcus iniae discitis in Singapore. Emerg Infect Dis 10:1694-1696

ㄴau SK, Woo PC, Fan RY, Lee RC, Teng JL, Yuen KY (2007) Seasonal and tissue distribution of Laribacter hongkongensis, a novel bacterium associated with gastroenteritis, in retail freshwater fish in Hong Kong. Int J Food Microbiol 113:62-66

Maness HT, Nollens HH, Jensen ED, Goldstein T and others (2011) Phylogenetic analysis of marine mammal herpesviruses. Vet Microbiol 149:23-29

Melo NR, Taguchi H, Jorge J, Pedro RJ and others (2004) Oral Candida flora from Brazilian human immunodeficiency virus-infected patients in the highly active antiretroviral therapy era. Mem Inst Oswaldo Cruz 99: 425-431

Murdoch ME, Reif JS, Mazzoil M, McCulloch SD, Fair PA, 
Bossart GD (2008) Lobomycosis in bottlenose dolphins (Tursiops truncatus) from the Indian River Lagoon, Florida: estimation of prevalence, temporal trends, and spatial distribution. EcoHealth 5:289-297

Pier GB, Madin SH (1976) Streptococcus iniae sp. nov., a beta-hemolytic streptococcus isolated from an Amazon freshwater dolphin, Inia geoffrensis. Int J Syst Bacteriol 26:545-553

Pier GB, Madin SH, Al-Nakeeb S (1978) Isolation and characterization of a second isolate of Streptococcus iniae. Int J Syst Bacteriol 28:311-314

Reif JS, Peden-Adams MM, Romano TA, Rice CD, Fair PA, Bossart GD (2009) Immune dysfunction in Atlantic bottlenose dolphins (Tursiops truncatus) with lobomycosis. Med Mycol 47:125-135

Rivera R, Robles-Sikisaka R, Hoffman EM, Stacy BA, Jensen ED, Nollens HH, Wellehan JJ (2012) Characterization of a novel papillomavirus species (ZcPV1) from two California sea lions (Zalophus californianus). Vet Microbiol 155: 257-266

Sun JR, Yan JC, Yeh CY, Lee SY, Lu JJ (2007) Invasive infection with Streptococcus iniae in Taiwan. J Med Microbiol 56:1246-1249

Editorial responsibility: Steven Raverty, Abbotsford, British Columbia, Canada
Takahashi $\mathrm{H}$, Ueda $\mathrm{K}$, Itano EN, Yanagisawa $\mathrm{M}$ and others (2010) Candida albicans and C. tropicalis isolates from the expired breathes [sic] of captive dolphins and their environments in an aquarium. Vet Med Int 2010:349364

Weinstein MR, Litt M, Kertesz DA, Wyper P and others (1997) Invasive infections due to a fish pathogen, Streptococcus iniae. N Engl J Med 337:589-594

Woolhouse ME, Gowtage-Sequeria S (2005) Host range and emerging and reemerging pathogens. Emerg Infect Dis 11:1842-1847

Zappulli V, Mazzariol S, Cavicchioli L, Petterino C, Bargelloni L, Castagnaro M (2005) Fatal necrotizing fasciitis and myositis in a captive common bottlenose dolphin (Tursiops truncatus) associated with Streptococcus agalactiae. J Vet Diagn Invest 17:617-622

* Zhang Z, Schwartz S, Wagner L, Miller W (2000) A greedy algorithm for aligning DNA sequences. J Comput Biol 7: 203-214

* Zhou SM, Xie MQ, Zhu XQ, Ma Y, Tan ZL, Li AX (2008) Identification and genetic characterization of Streptococcus iniae strains isolated from diseased fish in China. J Fish Dis 31:869-875

Submitted: March 22, 2016; Accepted: October 12, 2016

Proofs received from author(s): January 17, 2017 